\title{
Autism Spectrum Disorders in High Secure Psychiatric Care: A Review of Literature, Future Research and Clinical Directions
}

\author{
Murphy, D., \& Allely, C. S.
}

\section{Introduction}

Autism spectrum disorder (ASD) refers to a group of neurodevelopmental disorders including Autism, high functioning autism, Asperger's syndrome and atypical autism. Although different diagnostic classification systems have been adopted over the years, contemporary criteria follow those set out in the Diagnostic and Statistical Manual of Mental Diseases version five - DSM 5 by the American Psychiatric Association (APA, 2013) and the International Classification of Diseases eleventh edition by the World Health Organisation ICD 11 (WHO, 2018) that group all under the single category of Autism Spectrum Disorders. Prevalence studies suggest that ASD is not rare with approximately one in a hundred individuals in the general population (Baird, Simonoff, Pickles, Chandler, Loucas et al. 2006). Although males are more likely to receive the diagnosis of an ASD (Brugha, McManus, Bankart, Scott, Purdon et al., 2011; Loomes, Hull, \& Mandy, 2017), it is likely that the prevalence rate among women is significantly underestimated (Beggiato, Peyre, Maruani, Scheid, Rastam et al. 2016) and with the reasons poorly understood (Adamou, Johnson, \& Alty, 2018). Additional studies also suggest that the skewed male / female ratio is unevenly distributed across the spectrum (Kikovski et al. 2013) and may actually decrease as the symptom severity of ASD increases (Werling \& Geschwind, 2013). Having an ASD is also considered to be life-long. Whilst the causation behind having an ASD remains 
unknown, likely explanations include genetic / environmental interactions (Chaste \& Leboyer, 2012) resulting in atypical brain maturation and a disconnection between key brain regions (Ecker, 2016). It is also common for individuals with an ASD to have other neurodevelopmental disorders such as attention-deficit/hyperactivity disorder (ADHD) (Matson, Rieske \& Williams, 2013; Taylor, Charman, \& Ronald, 2015; Antshel, ZhangJames, Wagner, Ledesma, \& Faraone, 2016) and intellectual difficulties (Matson \& Shoemaker, 2009), neurological issues such as epilepsy (Brookes-Kayal, 2010) and sensory difficulties related to vision and hearing (Kancherla, Naarden Braun \& Yeargin-Allsopp, 2013). Co-morbid psychiatric disorder including anxiety, depression, obsessive compulsive disorder and a psychosis may also be present (Ghaziuddin, Ghaziuddin, \& Greden, 2002; Hammond \& Hoffman, 2014; Matson \& Williams, 2014; Moss, Howlin, Savage, Bolton, \& Rutter, 2015; Maddox \& White, 2015; Bruggink, Huisman, Vuijk, Kraaij, \& Garnefski, 2016).

\section{ASD symptomology and offending}

Whilst it is accepted that the majority of individuals with an ASD are law abiding, individual experiences vary enormously and for some they can be a perpetrator of an offence. However, despite the misleading impression provided by some high profile media cases, there is no evidence to suggest that individuals with an ASD are more likely to offend (Brewer, Zoanetti, \& Young, 2017; Im, 2016; King \& Murphy, 2014). Where an individual may present with behaviours that result in contact with the criminal justice system it is also typically found that offending is due to a combination of environmental circumstances and the specific difficulties associated with having an ASD (Gómez de la Cuesta, 2010). There is also an increasing number of peer reviewed publications highlighting how ASD symptomology can, in some 
cases, contribute to certain types of offending behaviour such as arson (Radley \& Shaherbano, 2011); sexual offending (Sevlever, Roth, \& Gillis, 2013; Allely \& CreabyAttwood, 2016; Creaby-Attwood \& Allely, 2017) and child pornography (Allely \& Dubin, 2018; Allely, Kennedy, \& Warren, under review).

Whilst every individual with an ASD is unique with regard to their circumstances and difficulties, all display the 'triad of impairments' (Wing 1981), i.e. present with significant difficulties in social communication, reciprocal social interaction and in different dimensions of imagination (typically experiencing problems with perspective taking, having a literal thinking style, a preference for routines and predictability, developing preoccupations, as well as having a restricted range of circumscribed interests). Additional 'hidden' difficulties may include different sensory hypersensitivities (Bogdashina, 2003), emotional regulation issues (Mazefsky, Herrington, Siegel, Scarpa, Maddox, Scahill, \& White, 2013) and heightened anxiety levels (Mazefsky, Folstein, \& Lainhart, 2008). Although individuals with an ASD can present with general levels of intellectual functioning ranging from 'extremely low' to 'very superior', other social and non-social cognitive characteristics can be present (Ambery, Russell, Perry, Morris, \& Murphy, 2006). For example, individuals with an ASD may have a literal thinking style, a tendency to focus on the details, as well as have specific features to their autobiographical memory functioning such as taking longer to recall such memories and requiring additional prompting to recall actions (Maras, Memon, Lambrechts, \& Bowler, 2013). In terms of inferring the mental states of others, individuals with an ASD can have particular difficulties with a 'theory of mind', i.e. making accurate judgements about the mental states of others (Baron-Cohen, 2000), as well as being less likely to refer to their own mental states during discussion (Gaus, 2007) and with self-monitoring during social situations (Baez, Rieffe, Gonzalez-Gadea, et al. 2012). Within dynamic social situations, is 
the observation that individuals with an ASD can have particular difficulties inferring sarcasm (Mathersul, McDonald, \& Rushby, 2013).

\section{Psychiatric Co-morbidity in Forensic Cases}

Psychiatric co-morbidity appears to be a significant factor with many forensic cases (Newman \& Ghaziuddin, 2008; Långström, Grann, Ruchkin, Sjöstedt, \& Fazel, 2009). In terms of violent offending Wachtel and Shorter (2013) suggest that individuals with an ASD may be particularly vulnerable to acting on symptoms of a psychosis, whilst Heeramun, Magnusson, Hellner Gumpert, Granath, Lundberg and others (2017) suggest that it is the association between ASD, ADHD and conduct disorder that makes some individuals more vulnerable to violent crime. In another study examining the link between ASD and psychiatric disorder, Søndenaa and colleagues (2014) investigated all forensic examination reports over a ten-year duration in Norway where there was a charge of either a violent or a sexual offense and the individual had an ASD diagnosis. The findings from their study showed that there were more severe mental health problems and less intellectual problems in the violent offenders when compared to the sex offenders.

\section{ASD in the Prison Environment}

The two reviews to date that have examined the experiences of individuals with ASD in the prison environment (Robertson \& McGillivary, 2015; Allely, 2015) both highlight the difficulties individuals with an ASD have within prisons as a result of the mismatch between an individual's difficulties with the social demands and physical constraints of such environments. Worse case scenarios have suggested that individuals with ASD can be more 
vulnerable to bullying, exploitation, sexual and physical victimisation, social isolation and confrontations with other inmates (English \& Heil, 2005). Having a developmental disability may also been found to be a risk factor for experiencing reduced empathy from correctional staff (Shively, 2004). The need for an overall prison strategy for dealing with individuals who have an ASD has been suggested by Lewis, Pritchett, Hughes, and Turner (2015).

\section{ASD in Secure Psychiatric Care}

Allely (2018) completed a literature review of ASD in low, medium and high secure psychiatric care (HSPC). Although a number of issues were raised such as a general over prevalence of ASD in such environments, these were in the context of a limited number of published studies. Within the UK, individuals with an ASD admitted to HSPC represent a specific subgroup of individuals with an ASD who offend and have contact with forensic psychiatric services. Like all admissions to HSPC, individuals with an ASD present with a serious and immediate risk of harm to others and or themselves. All individuals are also considered to have a mental disorder and detained under the Mental Health Act (1983) (DoH, 1983). Most individuals admitted into a HSPC hospital are from prisons or other less secure psychiatric units. HSPC hospitals within England include Broadmoor, Rampton and Ashworth Hospitals. All represent the highest level of secure psychiatric care. Each is managed by different NHS trusts but follow similar security protocols and standards of care (NHS commissioning board, 2013). At the time of writing, Rampton Hospital is the only HSPC facility in the UK that offers care to both women and individuals with a learning disability. Scotland and the Republic of Ireland each have their own HSPC facilities, the state hospital 'Carstairs' and 'Dundrum' respectively. However, these follow different operational guidelines and are accountable to different government organisations. 


\section{Present Review}

The aim of the current paper is to review in detail the research to date on individuals with an ASD detained specifically in HSPC highlighting key findings and limitations. Five areas of research are described reflecting the topics addressed to date including: the prevalence of ASD within HSPC; a discussion of the findings examining what cognitive and clinical differences have been found between individuals with an ASD and other patient groups; a discussion of the views of staff who work in HSPC of individuals with an ASD; a discussion of the experiences and quality of life of individuals with an ASD in HSPC, some discussion of how individuals engage with psychological interventions and the role of ASD awareness training. Although the review by Allely (2018) included studies investigating ASD within HSPC, the present review builds on this previous review by providing an experienced clinician's perspective and analysis of the findings and issues raised in the papers which investigated ASD in relation to specifically HSPC. In addition, the review concludes with a personal reflection on possible future research targets and the development of a HSPC clinical service for ASD.

\section{Methodology}

A literature review following a search of the online databases including Google Scholar, MEDLINE and PsycINFO. The search parameters included high secure psychiatric care, special hospital, autism, autism spectrum disorders, autism spectrum conditions and Asperger's syndrome. No exclusion criteria were employed. 


\section{Prevalence of ASD within HSPC}

To date, four UK studies have examined the prevalence of ASD within HSPC and all have suggested figures higher than the one percent prevalence for ASD in the general population (Baird, Simonoff, Pickles, Chandler, Loucas et al., 2006). The first study describing the prevalence of individuals with an ASD in a single HSPC was by Scragg and Shah (1994). In this widely cited study, following an initial screen of 392 male patient files it was found that 17 individuals were identified as possibly having Asperger's syndrome and who were subsequently interviewed with their primary nurses. From these, nine individuals $(2.3 \%)$ were considered to meet the formal diagnostic criteria for Asperger's syndrome as defined by Gillberg and Gillberg (1989). Three of these nine individuals were also considered to be 'equivocal' in meeting some, but not all of the diagnostic criteria. The uncertainty of two of this group being linked in part to a lack of detailed information on an individual's developmental history and one individual declining to be interviewed.

The second study by Hare, Gould, Mills and Wing (1999), examined the prevalence of ASD in all three of England's HSPC hospitals. Using a two stage survey methodology including a nine item staff questionnaire to identify possible individuals, followed by an examination of individual patient records and completion of the Handicaps, Behaviours and Skills (HBS) schedule (Wing, 1980), 31 individuals (2.4\%) out of a total of 1305 patients were identified as having an ASD. An additional 31 cases were rated as being 'equivocal', i.e. who had significant features of an ASD, but not enough information to receive a formal diagnosis. Within the ASD group, 29 (93.5\%) were male and no significant group differences were found in their ages at the time of assessment or in the length of detainment within hospital. Other observations included most individuals in the ASD group receiving the diagnosis of 
schizophrenia and a high number had some form of neurological disturbance. Although Hare and colleagues (1999) found a small number of females who met the formal criteria for an ASD, in a third study of a single HSPC hospital it was found (using a two stage assessment process including an initial screen of the entire female population followed by a standard diagnostic interview, review of case notes and completing a basic social inference task Dewey's stories) that around six $(11 \%)$ of the total females detained $(\mathrm{n}=51)$ met ICD 10 criteria for an ASD. Five individuals (approximately 10\%) were also rated as being 'uncertain', i.e. who displayed some, but not all features consistent with an ASD (Crocombe, Mills, \& Wing, 2006). The fourth study by Myers (2004), examined 57 forensic settings within Scotland, including four prisons, two secure accommodation units and the HSPC hospital Carstairs. Although the prevalence rates of individual units are not described, a generally low number of individuals with an ASD is reported including $0.93 \%$ in prisons, $0.46 \%$ in secure units and $1.39 \%$ in mental health units. It was also reported that following staff interviews, many raised concerns that the number of individuals formally identified with an ASD probably fell short of the actual number.

Whilst all these prevalence studies are useful, they are a little dated in terms of how individuals with an ASD are recognised and assessed in HSPC. Of significance is the observation that none of these prevalence studies used the accepted gold standard diagnostic tools including the Autism Diagnostic Observation Schedule $2^{\text {nd }}$ Edition (Lord, Rutter, DiLavore, Risi, Gotham, \& Bishop, 2012) and the Autism Diagnostic Interview Revised (Rutter, LeCouteur, \& Lord, 2003) that form the basis of most contemporary diagnostic studies. Although a qualitative impression of the author, it appears that whilst the exact number of individuals with an ASD within one HSPC hospital varies over the course of a year with admissions in and transfers out, the overall percentage of patients with an ASD may 
actually have increased slightly with around $4 \%$ of patients (out of a total of 198 patient) being identified as having an ASD in a recent study of patient incompatibilities and seclusions (Murphy, Bush, \& Puzzo, 2017). Of additional significance is the observations made by Scragg and Shah (1994) and Hare and colleagues (1999) that there are a number of individuals who present with 'equivocal' features and difficulties associated with having an ASD, but who refuse to engage with a full assessment or who may have many, but not sufficient features to receive a diagnosis. If these individuals were also included within prevalence estimates of ASD in HSPC, it may be that the overall figure for individuals with an ASD is higher. Future prevalence studies are required using contemporary diagnostic methods and which cover all HSPC hospitals. Within a historical context, it is also likely that individuals with an ASD have been detained within HSPC since their formation. There are also a number of high profile historical cases (such as the poisoner Graham Young) that although not formally diagnosed with an ASD during their lifetime, almost certainly would have received the diagnosis (e.g. Bowden, 1996).

\section{Differences between patients who have an ASD and other patients?}

Whilst Hare and colleagues (1999) did not find any significant differences between their identified ASD and non-ASD groups in age at assessment or in the length of detainment in hospital, subsequent studies within one HSPC hospital have found several differences in presenting characteristics and difficulties of ASD patients compared to other patient groups. For example, in comparison to patients with a schizophrenia and those with a personality disorder broadly matched on age and located on the same wards, patients with an ASD have been found to be less likely to have a significant history of alcohol and illicit substance misuse. There was also a rough split within the ASD group of patients between those 
admitted under the Personality Disorder and the Mental Illness classifications of the Mental Health Act (1983). Compared to patients with a personality disorder and a mental illness, within a violence rating scale (VRS; Gunn \& Robertson, 1976) patients with an ASD also had lower violence ratings for their index offence (the offence which resulted in their admission to the hospital) and lower total violence ratings (the sum of the violence ratings for an individual's index offence and offending histories), i.e. were likely to have offences that were rated as having 'minimal' (mostly verbal aggression) or 'moderate' violence (a physical assault that did not result in serious injury). Consistent with many case descriptions in the literature, it was also noted that the offences committed by individuals with an ASD were unusual in both circumstance and actions. In terms of basic neuropsychological functioning, whilst patients with an ASD had similar general levels of intellectual functioning (full scale IQ) compared to patients with a personality disorder, both groups had significantly higher general levels of intellectual functioning than patients with a schizophrenia (Murphy, 2003). In another study comparing performance within a social perceptual theory of mind task (the revised eyes task developed by Baron-Cohen, Wheelright, Hill, Raste, \& Plumb, 2001), patients with an ASD were found to perform at a similar level to those with the diagnosis of schizophrenia, i.e. make a similar errors in matching a mental state word to a photographic image of a pair of eyes, despite having significantly higher general levels of intellectual functioning (Murphy, 2006).

In terms of how individuals admitted to HSPC are screened for the possibility of an ASD during their admission to the hospital, research using the Autism Spectrum Quotient (AQ; Baron-Cohen, Wheelright, Skinner, Martin, \& Clubley, 2001), has found that after examining the profiles of 105 male patients (approximately $47.7 \%$ of the total patient population) individuals with an ASD had significantly higher total scores than patients with a diagnosis of 
schizophrenia and those with a diagnosis of personality disorder (Murphy, 2011). However, examination of the five AQ subscales found that it was social skills, communication and attention switching that were particularly sensitive, rather than attention to detail and imagination. Additional analysis also revealed that AQ scores were unrelated to full scale IQs, performance within the revised eyes task and some basic measures of executive functioning (notably the Hayling Sentence Completion and Brixton Spatial Anticipation tasks). Examination of the relationship between the AQ total scores and the Millon Clinical Multi-axial personality Inventory (MCMI III; Millon, 1998) profiles also found following a multiple regression that $45.7 \%$ of the variance in the AQ total score could be predicted by the MCMI III scales, with significant predictor variables including histrionic, narcissistic, antisocial, sadistic / aggressive and borderline scales. More detailed analysis also found that it was the social skill, communication and attention switching subscales of the AQ that could be predicted rather than the attention to detail and imagination subscales. Although this study suggests that the AQ is a useful screening tool for ASD in HSPC, was also the observation that some items were outside the direct experience of many patients such as those asking if they found playing with children easy (Murphy, 2011). This issue along with others such as the existing AQ relying on relatively good written comprehension skills suggests that a forensic version of the AQ may be useful.

Although no formal comparison groups were included in the research, another study of HSPC patients with an ASD found that no individuals were rated to have significant features of psychopathy (Murphy, 2007a) as defined by Hare (1991) whose construct covers interpersonal, affective and behavioural / lifestyle dimensions. Examining the Hare Psychopathy Checklist Revised (PCL R; Hare, 2003) profiles of 13 individuals with an ASD, it was found that whilst there was variation in profiles, no individuals had PCL-R total scores 
above suggested North American or British cut-off figures for psychopathy (35 and 25, respectively). However, of interest was the finding that in comparison to other patients in the hospital ( $\mathrm{n}=112$, unpublished data), while the mean PCL-R total score for individuals with an ASD was similar to other non-ASD patients (15 versus 15.8), the factor 1 mean total was higher (7.9 versus 6.8), specifically for facet 2 (affective components). In contrast, the mean total score for factor 2 was lower (7 versus 9.1), specifically facet 1 (interpersonal features such as glibness and superficial charm, grandiose sense of self-worth, pathological lying and conning and manipulative behaviours). Additional analyses did not find any significant relationship between an individual's PCL-R rating and their performance within the revised eyes task, the modified advanced theory of mind task (a social cognitive theory of mind test in which a story is read to an individual and they are asked to infer the meaning behind a story character's intentions and behaviours), as well as a number of other offence details including age at first conviction, age at index offence and the number of formal convictions (Murphy, 2007ª). This research appears to be consistent with other research in suggesting that psychopathy and ASD are not necessarily associated and present differently (Bjørkly, 2009), but can sometimes be present for a minority (e.g. Rogers, Viding, Blair, Frith, \& Happé, 2006), as well as perhaps representing a specific subgroup of offenders with an ASD (e.g. Alexander, Langdon, Chester, Barnoux, Gunaratna, \& Hoare, 2016). In terms of emotional regulation, additional research examining the self-reported experience and expression of anger of patients with an ASD found a characteristic profile. For example, in an examination of the State Trait Anger Expression Inventory 2 (STAXI 2; Speilberger, 1999) profiles it was found that individuals with offending behaviours linked to preoccupations such as those directed towards other individuals (in comparison to those whose offending was not directly linked to a preoccupation) tended to have profiles suggesting high rates of 'suppressed' anger, as well as higher scores in the attention to detail scale of the AQ. In contrast, those 
individuals with offending not linked to any preoccupation tended to have more complex psychiatric presentations (Murphy, 2014). Further research examining the emotional regulation difficulties of individuals with an ASD admitted to HSPC is required including using other non- self-report measures, comparative groups and examining potential therapeutic interventions such as bio-feedback (Schoenberg \& David, 2014).

In terms of the everyday management issues, a recent study of patient incompatibilities and seclusions found that individuals with an ASD in one HSPC hospital appear to have a disproportionately higher number of both compared to patients without an ASD. Examining the hospital data during a one year time period found that for individuals with an ASD, $87.5 \%$ had at least one incompatibility with another patient compared to $50.5 \%$ of individuals without an ASD. Further examination of the proportion of ASD patients in the hospital (4.04\%) and patients with an ASD on the incompatibilities list (6.80\%) found a statistically significant difference. Examining the total incompatibility list found that of the 103 individuals listed, 20 (16.7\%) involved at least one patient with an ASD, with the average number of incompatibilities listed for ASD patients being 2.8 versus 1 for patients without an ASD. Reasons for incompatibilities between patients included either direct verbal threats of physical aggression or and actual acts of physical aggression. In terms of seclusions, it was found that individuals with an ASD experienced both a higher number of long term seclusions (Long term seclusions is a specific HSPC care option used within the context the Mental Health Act 1983 implemented by respective clinical teams on wards) and more hours spent in long term seclusions compared to individuals without an ASD. In addition, of the six individuals with an ASD secluded, all had experienced more than two seclusions, putting them in the top $75 \%$ of secluded patients. Three of these individuals also experienced more than ten seclusions putting them in the top 25\% of secluded patients (Murphy, Bush, \& 
Puzzo, 2017). Although qualitative impressions and informal discussions with colleagues working in other secure settings suggest similar findings, a wider HSPC hospital survey is required to see if these findings are unique or apply to all. It would also be useful to examine whether other vulnerable groups of patients with other neurodevelopmental disorders or histories of acquired brain histories present with similar risk management issues.

\section{Views of staff}

To date, two UK studies have examined the views of staff working in HSPC concerning individuals with an ASD. Misra, Patel and Edwards (2013) completed an audit using a questionnaire sent to nursing staff $(n=100)$ of one HSPC hospital assessing their knowledge of autism and knowledge of best practise. The results suggested that whilst most staff reported some awareness of autism, most were unaware of the Autism Act (2009) and were unsure of how best to work with patients who had an ASD. In a more comprehensive study, Murphy and McMorrow, (2015), using a 15 item questionnaire, explored the views and experiences of a wider range of staff $(n=206)$ working in one HSPC hospital who had direct patient contact (with the staff group including psychologists, psychiatrists, nursing staff, occupational therapists, medical centre staff). Most staff reported knowing someone with an ASD outside of the work environment and most also reported working directly with a patient who they knew to have an ASD. In terms of everyday management, just over half the sample reported making some form of adjustment to their clinical practise to accommodate the needs of the individual with an ASD, as well as their interactions and expectations of individuals with an ASD. A similar number of staff also expressed the view that individuals with an ASD might benefit from being managed in a different way compared to other patients. Only a small percentage of the staff group $(22.3 \%)$ thought that the difficulties of patients with an 
ASD were considered in their care and most (64\%) thought that such patients were more vulnerable to bullying or intimidation than other patients. Most staff thought patients with an ASD 'definitely' or 'mostly' benefitted from the therapies on offer within the hospital. Other key findings from the survey included only a small number of staff (27\%) believing they had adequate skills and knowledge to work with individuals with an ASD. Most staff also expressed the wish for more training on ASD (92\%) and that such training should be mandatory $(76 \%)$. In terms of qualitative comments made by some staff, many felt that a specialist ASD service would be useful. Although these surveys are restricted to one HSPC setting and only reflect the views of those who returned questionnaires, they are a useful indication of what many staff think about their patients with an ASD. Future research across all HSPC hospitals would be helpful, as would an examination of the impact of ASD awareness training with staff on everyday practice and what staff qualities might be helpful when working with individuals who have an ASD in forensic settings (Worthington, 2016).

\section{Experience and quality of life of patients within HSPC}

Echoing the findings from other studies that suggest individuals with an ASD detained in prison environments have varied experiences (e.g. Allely, 2015), research within one UK HSPC hospital has suggested that experiences are equally varied. In the only study to date examining the experiences and quality of life of a small sample of individuals with an ASD in HSPC ( $=7$ ), Murphy and Mullens (2017) found a diverse range of backgrounds, offending behaviours, personal experiences, as well as relative vulnerabilities and objective measures of functioning (such as participation in occupational and therapeutic activities, number of problem incidents, periods in seclusion and views from staff). In terms of the negative aspects of care, individuals expressed the view that there were too many rules and restrictions that 
prevented them pursuing some personal interests (e.g. being unable to have a pair of binoculars to watch aircraft or not being allowed a computer). Many individuals also described the regular security searches (involving physical rub downs) and room searches as stressful where often personal possessions were not placed back in the same place. A frequent difficulty reported by many individuals was sharing their immediate environments with other individuals perceived as being difficult, unpredictable and disinhibited. Although reported by a minority of individuals, some expressed the view that they did not feel their difficulties were understood by staff. Among those with experience of being detained in a prison environment, most described having a stressful time there and that it was better in the forensic psychiatric system. For example, within HSPC, individuals described valuing the structure, predictability and routine of the hospital environment, as well as highly trained and sympathetic staff. Many individuals also described the therapies they had participated in the hospital such as dialectical behaviour therapy as being beneficial for them, as well as being actively involved in a range of occupational and educational activities. Most individuals also confirmed that their ASD had not been diagnosed until admission to HSPC. Of interest, were also the views of two patients transferred from specialist ASD medium secure care and who both reported having negative experiences with other ASD patients. Although it is not possible to generalise from these individuals, they do highlight the situation that even within specialist ASD units there can be negative experiences and the position that such units are not always appropriate for individuals with an ASD. They also highlight the finding that many individuals with an ASD express a preference for wards that have a mixture of individuals perhaps more representative of everyday life and who sometimes offer assistance or advice. Examining individual ratings in the Lancashire Quality of Life Profile questionnaire (LQoLP; Oliver, Huxley, Bridges, \& Mohammed, 1996) also found that most individuals reported having a similar or significantly better quality of life in many domains (including global, 
leisure, financial and living situation) compared to other detained forensic patient groups, including a HSPC admission sample. Whilst the reasons for such different experiences requires further exploration, clinical impressions suggest that some of those who report negative experiences also present with complex psychopathology including co-morbid mental illness and probable personality disorder. Whilst it is difficult to disentangle the relationship, the presence of a complex comorbid psychopathology such as a psychosis or a personality disorder may have implications on how staff view and manage such individuals, as well as an individual's relative awareness into their difficulties and presence of any other factors that may influence experiences such as paranoid ideation and views of authority. Objective measures of experience such as participation in activities, as well as any time spent in seclusion were also found to be unrelated to the views held by patients (Murphy \& Mullens, 2017). Although useful, this survey is only a snapshot of one particular patient group at a specific point in time. As is highlighted by the authors, there is much to be learnt from examining patient experiences with the need for more robust and regular surveys of the views and satisfaction ratings of this patient group and others across different forensic settings.

\section{Engagement with psychological interventions and role of staff ASD awareness training}

Although research suggests that individuals with an ASD in non-forensic contexts benefit from adapted psychological therapies such as social skills interventions, cognitive behaviour therapy and mindfulness (Gaus, 2007; Spain, O’Neil, Harwood, \& Chaplin, 2016), there remains a lack of detailed research into psychological and non-psychological therapies for offenders with an ASD (Melvin Langdon, \& Murphy, 2017). As Spain and colleagues (2016) also highlights in a review of non-forensic psychological interventions, there is a need to examine how therapeutic outcomes are assessed with individuals who have an ASD including 
what formal measures are employed and when, as well as using appropriate comparative data. In particular, there is a lack of understanding into what factors are associated with the best therapeutic outcomes. Perhaps linked to this lack of understanding is the observation that many individuals with an ASD who offend do so due to a complex interaction of intrinsic and extrinsic reasons within a specific set of circumstances (Murphy, 2013). Such gaps in understanding appear to be present across wider forensic services where for example the lack of appropriate interventions in prisons for individuals with an ASD with sexual offending histories has been highlighted (Higgs \& Carter, 2015).

However, whilst there is a lack of evidence regarding therapeutic engagement and responsivity for individuals with an ASD in HSPC, this may not necessarily reflect a lack of appropriate interventions or therapies. Indeed, qualitative impressions by the author supported by a patient experiences survey (Murphy \& Mullens, 2017) suggests that many individuals with an ASD do benefit from therapies such as dialectical behaviour therapy and individual education / mindfulness approaches. However, it is also true that engagement and outcomes do vary between individuals with some individuals struggling with any form of intervention requiring personal reflection or Socratic questioning. Anecdotally, clinical experience suggests that the diversity seen in this group of individuals appears strongly related to their cognitive functioning and any co-morbidity such as a psychosis. The ability to accurately infer one's own and other peoples' mental states appears to be a particularly significant influence on the ability to engage with and benefit from psychological therapies (individual or group based). Although based on a single case study, one example of an individual with an ASD admitted to HSPC following the conviction for murder was found to have significant difficulties across a range of social and non-social cognitive domains that prevented working in groups, as well as restricted their capacity to address a range of issues 
targeting the experience of ASD and accepting responsibility for offending behaviour. A key factor that appeared to have a big influence on this individual's capacity to benefit from conventional therapies was his significant social cognition difficulties, egocentricity and rather extreme literal thinking. Notably, these difficulties restricted the individual's ability to reflect on his behaviours and appreciate the perspectives of others (including lacking any victim empathy), as well as severely limit a consideration of alternative ways to have behaved (Murphy, 2010). Further evidence for the possible influence of social cognition on outcome in HSPC patients also comes from an examination of patients with schizophrenia, where performance in the revised eyes task was found to be related to subsequent ratings of risk and clinical need three years later (Murphy, $2007^{\mathrm{b}}$ ). A similar study of patients with an ASD would be useful that also includes measures of therapeutic engagement and different outcome indicators.

Probably the most influential factor on how individuals with an ASD are managed within HSPC is staff awareness and training in ASD. Although there is to date no research looking specifically at the effects of staff ASD awareness and training on the management of ASD patients in HSPC, as was reflected in the staff survey completed by Murphy and McMorrow (2015), most clinical staff expressed the view that autism awareness training should be mandatory and that many staff believe themselves not to have enough skills in working with this group of patients. It could also be argued that the most cost and clinically effective method of managing individuals with an ASD in HSPC is through staff awareness and training. Within one HSPC hospital, the author provides autism awareness training three times a year to all staff. During the training staff are provided with information on the autism spectrum, the associated difficulties and how to work with an individual's difficulties in a positive way. The SPELL guidelines (National Autistic Society, 2013) are also introduced to 
staff as a way of attempting to avoid problem incidents with individuals by being aware of their difficulties, making appropriate adjustments in any demands and working positively with individual strengths and weaknesses. Although any formal analysis of the impact of the SPELL approach on how individuals with an ASD are managed in the hospital remains to be completed (such as reducing the number of incidents), anecdotal post course feedback by staff to the author suggests that such training is useful.

\section{Best Practice Related to Assessment and Management}

Best practice related to the assessment and management of individuals with an ASD in HSPC will continue to evolve. In terms of current evidence, although individuals with an ASD represent a small proportion of the total patient population in HSPC, they are likely to be overrepresented relative to the general population prevalence. It is also likely that the available estimates are conservative and the actual figure for the number of individuals with an ASD in HSPC may be higher than those reported. This may be especially so if individuals with atypical features of an ASD are included, as well as those who are highly likely to have an ASD but refuse to complete assessments. Research to date also suggests that individuals with an ASD in HSPC present with difficulties and needs that are different from the other patient groups, as well as staff viewing individuals as particularly vulnerable and benefit from being managed in a different way. In terms of hospital experience, whilst most individuals with an ASD report positive experiences, as well as appearing to have a generally good quality of life, there is clearly room for improvement in creating a more autism friendly environment by making reasonable adjustments in ward design and how individuals are managed by staff (such as following the SPELL approach more consistently). Such adaptations are also essential when formally interviewing individuals with an ASD in 
forensic settings (Murphy, 2018). As highlighted, a limitation with the research to date is that much of it has been restricted to one UK HSPC hospital. As such, the findings may be difficult to generalise to other HSPC hospitals within and outside of the UK. Whilst informal discussions with other HSPC representatives regarding how individuals with an ASD are assessed and managed appear consistent with the research, there is a need for multi-site research examining various aspects of how individuals with an ASD are assessed and managed, as well as the respective experiences and views of both staff and patients. The presentations and experiences of female patients with an ASD in HSPC also remain to be adequately explored. Indeed, there is accumulating evidence suggesting that the presentation of women with an ASD differ from males in having repetitive behaviours and restricted interests that are more difficult to formally identify (Hull, Mandy, \& Petrides, 2017) and in displaying so called 'social camouflaging', where social skills are mimicked to mask underlying difficulties (Lai, Lombardo, Auyeung, Chakrabarti, \& Baron-Cohen, 2015; Robinson et al., 2013; Hull et al., 2017) (for a review see: Allely, accepted; Allely, under review).

Although the views of Wing (1997) outlined over twenty years ago that state the appropriate management of individuals with an ASD is dependent on an accurate diagnosis and staff training, a robust examination of how individuals with an ASD benefit from specific therapeutic interventions offered in HSPC remains to be carried out. Indeed, there is a noticeable absence of research that has adequately explored not only what therapies individuals with an ASD engage with in HSPC, but also what factors are associated with the best outcomes - however this is defined and over what time period. Whilst qualitative impressions of one author, supported by some individual experiences (Murphy \& Mullens, 2017) suggest that many interventions do make a positive difference, clinical experience 
suggests there are individual differences in the capacity to engage with and benefit from many insight orientated therapies. Indeed, many myths associated with ASD such as being unable to work in groups are inaccurate, at least for some individuals. Key research topics that remain to be addressed include those targeting having a much better understanding of the diversity of presentations present in this group of individuals. As highlighted, individuals with an ASD can present with a range of interpersonal, sensory, emotional regulation and cognitive profiles, as well as psychiatric and other neurodevelopmental co-morbidities. At present, our understanding of the relative influence of these profiles on risk and ability to engage with or benefit from psychological interventions is poor. Whilst the idea of typologies of ASD offenders has been suggested based on the co-morbidity with psychopathy and psychosis (Alexander, Langdon, Chester, Barnoux, Gunaratna \& Hoare, 2016), this may fail to adequately cover the likely interaction between psychiatric or other neurodevelopmental disorders (such as ADHD) with cognitive profiles. Clinical impressions suggest that an individual's social cognition abilities appears to be a particularly important factor in determining their engagement with and ability to benefit from many psychological interventions, as well as influencing their own judgements regarding risk for future interpersonal violence. Possible projects for future exploration include both prospective designs where following a detailed initial assessment of individuals with an ASD, they are periodically reviewed through their detention in secure psychiatric services to examine what factors appear related to better outcomes. In addition, the histories of individuals with an ASD in the hospital could be reviewed to identify what factors appear to have been linked with therapeutic engagement and subsequent outcomes. Given the ethical issues of many forensic cases and heterogeneity of individuals with an ASD in their profiles of strengths and weaknesses, using randomised clinical trials would not appear appropriate. A more ethical and informative approach might be to complete systematic case studies. Other potential 
influences on outcome such as staff perceptions of an individual's difficulties also remain an important research topic. Again clinical impressions suggest that some individuals with an ASD, especially those with likely co-morbid personality disorders often create differences in opinion between staff which may subsequently influence management 'styles' and care decisions. Thus, some staff may view an individual's behaviour as a result of the difficulties associated with ASD, whilst others may view it as a product of an anti-social personality. Such differences in opinion can have significant implications for an individual's future care management, including in some circumstances whether to return an individual to prison or to remain within the psychiatric system. There may therefore be an argument that all staff should receive mandatory training in ASD (Murphy \& McMorrow, 2015). Although such training may not completely remove inconsistencies with how individuals are managed, it might encourage more thought into how an individual's behaviour is interpreted. With an understanding of the factors influencing outcome may come better targeting of specific interventions to individuals.

Future research targets

\section{Use of New Technologies in Assessments and Therapeutic Interventions}

There is a growing body of research suggesting that virtual reality is useful for individuals with an ASD in terms of assessment and as a therapeutic aid (Bellini, Fornasari, Chittaro, \& Brambilla, 2011). With the potential to simulate specific environments and high degree of experimental control, it is likely that virtual reality will play a crucial role in risk assessments of individuals with an ASD in HSPC, as well as perhaps offer novel therapeutic approaches (Benbouriche, Nolet, Trottier, \& Renaud, 2014; Fitzgerald, Yap, Ashton, Moore, Furlonger, Anderson, \& English et al., 2018; Parsons, 2016). 


\section{Understanding Psychological Trauma in ASD patients admitted to HSPC}

Consistent with the trauma informed care approach being adopted in many inpatient forensic services (Levenson, \& Willis, 2018) is the recognition that many individuals with an ASD who have contact with such services have histories involving psychological trauma (Im, 2016a). There is also the suggestion that individuals with an ASD may be at greater risk for experiencing stressful and traumatic life events (Fuld, 2018) and that such experiences may increase the likelihood of co-morbid psychiatric disorders (Mannion, Brahm, \& Leader, 2014), as well as a potential worsening of the core ASD difficulties (Kerns, Newschaffer, \& Berkowitz, 2015; Taylor, \& Gotham, 2016). There is also the possibility that many symptoms associated with trauma such as aggression, concentration difficulties, social isolation, increased relational difficulties, regression in daily living skills and an increase in the amount of repetitive or stereotypic behaviour may be confused with the difficulties associated with having an ASD (Bishop-Fitzpatrick, Mazefsky, Minshew, \& Eack, 2015; García-Villamisar \& Rojahn, 2015; Kerns, Newschaffer, \& Berkowitz, 2015, Allely \& Faccini, under review). In terms of the relationship between violence and trauma in ASD, Im (2016a) suggests that individuals with ASD may "possess sensitized prefrontal-cortical-limbic networks that are overloaded in the face of trauma, leading to unchecked limbic output that produces violent behaviour, and/or cognitive dysfunction (including difficulties with theory of mind, central coherence and executive function) that impacts trauma processing in ways that portend violence". As with many forensic groups, there is the need for a much greater clinical and research focus examining the potential link between violent behaviour and history of trauma among individuals with ASD admitted to HSPC.

\section{Creating a Clinical Service for Patients who have an ASD in HSPC}


In terms of a specific clinical service for patients who have an ASD in HSPC, whilst there is no evidence to suggest that a specialist ward is required or desired, there does appear to be a need to develop an ASD service. Such a service would include several wards such as admissions, assertive rehabilitation and high dependency units that are particularly sensitive to the difficulties and needs of patients with an ASD. Any service would also ideally include a designated clinical team that monitors an individual's care throughout their hospital stay, having ward staff well trained in ASD and where reasonable adjustments are made to procedures and ward design such as position of rooms and addressing any sensory issues. It may also be useful to preselect staff with the 'right' qualities and skills to work with such individuals (Worthington, 2016). In addition, consistent with the spirit of several government pieces of legislation such as the Autism Act (2009), Think Autism (2014), the Equalities Act (2010) and Transforming Care (2017) in the UK, there is an argument for HSPC to obtain accreditation from the National Autistic Society as achieved by some UK prisons (Lewis, Pritchett, Hughes, \& Turner, 2015). However, whilst the accreditation process may set out a helpful framework for best practice, the clinical demands and risk management issues of HSPC are quite unique. The importance of following best practice and research is not only important within the context of the cost associated with managing individuals in HSPC, but may also be especially important in avoiding past controversies associated with detaining individuals with an ASD (e.g. 'Broadmoor knew risk in holding Asperger's patients' reported by the Telegraph newspaper during November 2003). 


\section{References}

Adamou, M., Johnson, M., \& Alty, B. (2018). Autism Diagnostic Observation Schedule (ADOS) scores in males and females diagnosed with Autism: a naturalistic study. Advances in Autism, (just-accepted).

Alexander, R., Langdon, P., Chester, V., Barnoux, M., Gunaratna, I. \& Hoare, S. (2016). Heterogeneity within autism spectrum disorder in forensic mental health: the introduction of typologies. Advances in Autism. 2 (4), 201- 209.

Allely, C. (2015). Experiences of prison inmates with autism spectrum disorders and the knowledge and understanding of the spectrum among prison staff: a review. Journal of Intellectual Disabilities and Offending Behaviour. 6, (2), 55 - 67.

Allely, C., \& Creaby-Attwood, A. (2016). Sexual offending and autism spectrum disorders. Journal of Intellectual Disabilities and Offending Behaviour, 7(1), 35-51.

Allely, C. (2018). A systematic PRISMA review of individuals with autism spectrum disorder in secure psychiatric care: prevalence, treatment, risk assessment and other clinical considerations. Journal of Criminal Psychology. 8 (1), 58 \& 79.

Allely, C. S. (submitted revisions). Exploring the female autism phenotype of repetitive behaviours and restricted interests (RBRIs): A literature review. Advances in Autism. 
Allely, C. S., \& Faccini, L. (under review). A commentary regarding the research and practical suggestions for addressing trauma in Autism Spectrum Disorders.

Allely, C. S. (in press). Understanding and recognising the female phenotype of autism spectrum disorder and the "camouflage" hypothesis: A systematic PRISMA review. Advances in Autism.

Allely, C. S., \& Dubin, L. (2018). The contributory role of autism symptomology in child pornography offending: Why there is an urgent need for empirical research in this area. Journal of Intellectual Disability and Offending Behaviour. 9(4), 129-152.

American Psychiatric Association. (2013) Diagnostic and Statistical Manual of mental disorders $5^{\text {th }}$ edition. Washington DC.

Ambery, F., Russell, A., Perry, K., Morris, R., \& Murphy, D. (2006). Neuropsychological functioning in adults with Asperger's syndrome. Autism. 10, (6), 551 - 564.

Antshel, K. M., Zhang-James, Y., Wagner, K. E., Ledesma, A., \& Faraone, S. V. (2016). An update on the comorbidity of ADHD and ASD: a focus on clinical management. Expert Review of Neurotherapeutics, 16(3), 279-293. 
Autism Act (2009). Accessed at www.legislation.gov.uk/ukpga/2009/15/contents

Baez, Rieffe, Gonzalez-Gadea, et al. (2012). Integrating intention and context: assessing social cognition in adults with Asperger's syndrome. Frontiers Human Neuroscience. 6, (1), $1-21$

Baird, G., Simonoff, E., Pickles, A., Chandler, S., Loucas, T., Meldrum, D. \& Charman, T. (2006). Prevalence of disorders of the autism spectrum in a population cohort of children in South Thames: the special needs and autism project (SNAP). Lancet. 368, $210-215$.

Baron-Cohen, S. (2000). Understanding other minds: Perspectives from Developmental Cognitive Neuroscience. Oxford University Press.

Baron-Cohen, S., Wheelright, S., Hill, J., Raste, R. \& Plumb, I. (2001). The 'Reading the Mind in the Eyes' Test Revise version: A study of Normal Adults and Adults with Asperger's Syndrome or High Functioning Autism. Journal of Child Psychology and Psychiatry. 42, (2), $241-251$

Baron-Cohen, S., Wheelright, S., Skinner, R., Martin, J. \& Clubley, E. (2001). The Autism spectrum Quotient (AQ): Evidence from Asperger Syndrome / High Functioning Autism, Males and Females, scientists and mathematicians. Journal of Autism and Developmental Disorders. 31, (1), $5-17$. 
Beggiato, A., Peyre, H., Maruani, A., Scheid, I., Rastam, M., Amsellem, F., Gillberg, C., Leboyer, M., Bourgeron, T., Gillberg, C. \& Delorme, R. (2016). Gender differences in autism spectrum disorders: divergence among specific core symptoms. Autism Research. 10, 4, 680 $-689$.

Bellani, M., Fornasari, L., Chittaro, L., \& Brambilla, P. (2011). Virtual reality in autism: state of the art. Epidemiology and Psychiatric Sciences. 20, 3, 235 - 238.

Benbouriche, M., Nolet, K., Trottier, D. \& Renaud, P. (2014). Virtual reality applications in forensic psychiatry. In proceedings of the virtual reality international conference. Laval Virtual (VRIC' 14). April 9 - 11, 2014, Laval, France.

Bishop-Fitzpatrick, L., Mazefsky, C. A., Minshew, N. J., \& Eack, S. M. (2015). The relationship between stress and social functioning in adults with autism spectrum disorder and without intellectual disability. Autism Research, 8(2), 164-173.

Bjørkly, S. (2009). Risk and dynamics of violence in Asperger's syndrome: a systematic review of the literature. Aggression and Violent Behaviour. 14, (5), $306-312$.

Bogdashina, O. (2003). Sensory Perceptual Issues in Autism and Asperger Syndrome. Jessica Kingsley Publishers. London and Philadelphia. 
Bowden, P. (1996). Graham Young (1947 - 1990); the St Albans poisoner: his life and times. Criminal Behaviour and Mental Health. 17 - 24. 17 - 24.

Brewer, N., Zoanetti, J., \& Young, R. L. (2017). The influence of media suggestions about links between criminality and autism spectrum disorder. Autism, 21(1), 117-121.

Brookes-Kayal, A. (2010). Epilepsy and autism spectrum disorders: are there common developmental milestones? Brain and Development. 32, (9), 731 - 738.

Brugha, T. S., McManus, S., Bankart, J., Scott, F., Purdon, S., Smith, J., \& Meltzer, H. (2011). Epidemiology of autism spectrum disorders in adults in the community in England. Archives of General Psychiatry, 68(5), 459-465.

Bruggink, A., Huisman, S., Vuijk, R., Kraaij, V., \& Garnefski, N. (2016). Cognitive emotion regulation, anxiety and depression in adults with autism spectrum disorder. Research in Autism Spectrum Disorders, 22, 34-44.

Chaste, P. \& Leboyer, M. (2012). Autism risk factors: genes, environment and geneenvironment interactions. Dialogues in Clinical Neuroscience. 14, (3), 281 \& 292. 
Creaby-Attwood, A., \& Allely, C. S. (2017). A psycho-legal perspective on sexual offending in individuals with Autism Spectrum Disorder. International Journal of Law and Psychiatry, $55,72-80$.

Crocombe, J., Mills, R. \& Wing, L. (2006). Autism spectrum disorders in the high security hospitals of the United Kingdom. A summary of two studies. The National Autistic Society, London.

Daily telegraph (2003). Broadmoor knew risk in holding Asperger's patients' reported by the Telegraph newspaper during November 2003.

Department of Health (1983). Mental Health Act (1983). Amended 2015 and 2007. London, HMSO.

Esan, F., Chester, V., Gunaratna, I. J., Hoare, S., \& Alexander, R. T. (2015). The clinical, forensic and treatment outcome factors of patients with autism spectrum disorder treated in a forensic intellectual disability service. Journal of Applied Research in Intellectual Disabilities, 28(3), 193-200.

Ecker, C. (2016). The neuroanatomy of autism spectrum disorder: an overview of the structural neuroimaging findings and their translatability to the clinical setting. Autism. 21 (1), $18-28$. 
Ehlers, S., \& Gillberg, C. (1993). The epidemiology of Asperger syndrome: A total population study. Child Psychology and Psychiatry and Allied Disciplines, 34 (8), 13271350.

English, K., \& Heil, P. (2005). Prison rape: What we know today. Corrections Compendium, $30(5), 1-5$.

Equalities Act (2010). Legislation.gov.uk. (2010). Equality Act 2010. Retrieved from https://www.legislation.gov.uk/ukpga/2010/15

Fitzgerald, E., Yap, H. K., Ashton, C., Moore, D. W., Furlonger, B., Anderson, A. \& English, D. L. (2018). Comparing the effectiveness of virtual reality and video modelling as an intervention strategy for individuals with Autism Spectrum Disorder: Brief report Developmental Neurorehabilitation, 21(3), 197-201

Fuld, S. (2018). Autism Spectrum Disorder: The impact of stressful and traumatic life events and implications for clinical practice. Clinical Social Work Journal, 1-10. 
García-Villamisar, D., \& Rojahn, J. (2015). Comorbid psychopathology and stress mediate the relationship between autistic traits and repetitive behaviours in adults with autism. Journal of Intellectual Disability Research, 59(2), 116-124.

Gaus, V. (2007). Cognitive Behaviour Therapy for Adult Asperger Syndrome. The Guildford Press. New York and London.

Ghaziuddin, M., Ghaziuddin, N., \& Greden, J. (2002). Depression in persons with autism: Implications for research and clinical care. Journal of Autism and Developmental Disorders, 32(4), 299-306.

Gillberg C. \& Gillberg, C. (1989). Asperger's syndrome - some epidemiological considerations. A research note. Journal of Child Psychology and Psychiatry. 30, 631 - 638.

Gómez de la Cuesta, G. (2010). A selective review of offending behaviour in individuals with autism spectrum disorders. Journal of Learning Disabilities and Offending Behaviour. 1, (2), 47-58.

Gunn, J. \& Robertson, G. (1976). Drawing a Criminal Profile. British Journal of Criminology. 16, 156 - 160. 
Hammond, R. K., \& Hoffman, J. M. (2014). Adolescents with high-functioning autism: An investigation of comorbid anxiety and depression. Journal of Mental Health Research in Intellectual Disabilities, 7(3), 246-263.

Hare, D., Gould, J., Mills, R. \& Wing, L. (1999). A preliminary study of individuals with autistic spectrum disorders in three special hospitals in England. National Autistic Society. Available at www.aspires-relationships.com/3hospitals.pdf.

Hare, R. (1991). Hare Psychopathy Checklist - Revised (PCL - R). Toronto, ON: Multi Health Systems.

Hare, R. (2003). Hare Psychopathy Checklist Revised (PCL R) second edition. MNS. North Tonawanda.

Hartley, S. L., \& Sikora, D. M. (2009). Sex differences in autism spectrum disorder: an examination of developmental functioning, autistic symptoms, and coexisting behaviour problems in toddlers. Journal of Autism and Developmental Disorders, 39(12), 1715-22.

Haruvi-Lamdan, N., Horesh, D., \& Golan, O. (2017). PTSD and autism spectrum disorder: Co-morbidity, gaps in research, and potential shared mechanisms. Psychological Trauma: Theory, Research, Practice, and Policy, 10, 290-299. 
Heeramun, R., Magnusson, C., Hellner Gumpert, C., Granath, S., Lundberg, M., Dalman, C. \& Rai, D. (2017). Autism and convictions for violent crimes: population based cohort study in Sweden. Journal of the American Academy of Child and Adolescent Psychiatry. 56, 6, 491 $-497$.

Higgs, T. \& Carter, A. (2015). Autism spectrum disorder and sexual offending: responsivity in forensic interventions. Aggression and Violent Behaviour. 22, 112-119.

Hull, L., Petrides, K. V., Allison, C., Smith, P., Baron-Cohen, S., Lai, M. C., \& Mandy, W. (2017). "Putting on my best normal": social camouflaging in adults with autism spectrum conditions. Journal of Autism and Developmental Disorders, 47(8), 2519-2534.

Im, D. S. (2016). Template to perpetrate: An update on violence in autism spectrum disorder. Harvard Review of Psychiatry. 24, (1), $14-35$.

Im, D. S. (2016a). Trauma as a Contributor to Violence in Autism Spectrum Disorder. The Journal of the American Academy of Psychiatry and the Law, 44(2), 184-192.

Kancherla, V., Naarden Braun, K. \& Yeargin-Allsopp, M. (2013). Childhood vision impairment, hearing loss and co-occurring autism spectrum disorder. Disability and Health Journal. 6, (4), $333 \& 342$ 
Kawakami, C., Ohnishi, M., Sugiyama, T., Someki, F., Nakamura, K., \& Tsujii, M. (2012). The risk factors for criminal behaviour in high-functioning autism spectrum disorders (HFASDs): A comparison of childhood adversities between individuals with HFASDs who exhibit criminal behaviour and those with HFASD and no criminal histories. Research in Autism Spectrum Disorders, 6(2), 949-957.

Kenyon, S. (2014). Autism in Pink: Qualitative Research Report. Retrieved from Autism In Pink Website. http://autisminpink.net.

Kerns, C. M., Newschaffer, C. J., \& Berkowitz, S. J. (2015). Traumatic childhood events and autism spectrum disorder. Journal of Autism and Developmental Disorders, 45(11), 34753486.

King, C. \& Murphy, G. (2014). A systematic review of people with autism spectrum disorder and the criminal justice system. Journal of Autism and Developmental Disorders. 44, (1), $2717-2733$.

Kirkovski, M., Enticott, P. G., \& Fitzgerald, P. B. (2013). A review of the role of female gender in autism spectrum disorders. Journal of Autism and Developmental Disorders, 43(11), 2584-2603. 
Koenig, K., \& Tsatsanis, K. D. (2005). Pervasive developmental disorders in girls. In: Bell DJ, Foster SL and Mash EJ (eds) Handbook of Behavioural and Emotional Problems in Girls. New York: Kluwer Academic/Plenum Publishers, pp.211-237.

Kreiser, N. L., \& White, S. W. (2014). ASD in females: are we overstating the gender difference in diagnosis?. Clinical Child and Family Psychology Review, 17(1), 67-84.

Lai, M.-C., Lombardo, M. V., Auyeung, B., Chakrabarti, B., \& Baron-Cohen, S. (2015). Sex/gender differences and autism: setting the scene for future research. Journal of the American Academy of Child and Adolescent Psychiatry, 54(1), 11-24.

Långström, N., Grann, M., Ruchkin, V., Sjöstedt, G., \& Fazel, S. (2009). Risk factors for violent offending in autism spectrum disorder: a national study of hospitalized individuals. Journal of Interpersonal Violence, 24(8), 1358-1370.

Levenson, J. \& Willis, G. (2018). Implementing Trauma Informed Care in Correctional Treatment and Supervision. Journal of Aggression, Maltreatment and Trauma. https://doi.org/10.1080/10926771.2018.1531959.

Lewis, A., Pritchett, R., Hughes, C. \& Turner, K. (2015). Development and implementation of autism standards for prison. Journal of Intellectual Disabilities and Offending Behaviour. $6,(2), 68-80$. 
Loomes, R., Hull, L., \& Mandy, W. P. L. (2017). What is the male-to-female ratio in autism spectrum disorder? A systematic review and meta-analysis. Journal of the American Academy of Child and Adolescent Psychiatry, 56(6), 466-474.

Lord, C., Rutter, M., DiLavore, P., Risi, S., Gotham K., Bishop, S., Luyster, R. \& Guthrie, W. (2012). Autism Diagnostic Observation Schedule - 2. Pearson.

MacDonald, S., Clarbour, J., Whitton, C., \& Rayner, K. (2017). The challenges of working with sexual offenders who have autism in secure services. Journal of Intellectual Disabilities and Offending Behaviour, 8(1), 41-54.

Maddox, B. B., \& White, S. W. (2015). Comorbid social anxiety disorder in adults with autism spectrum disorder. Journal of Autism and Developmental Disorders, 45(12), 39493960.

Mandell, D. S., Walrath, C. M., Manteuffel, B., Sgro, G., \& Pinto-Martin, J. A. (2005). The prevalence and correlates of abuse among children with autism served in comprehensive community-based mental health settings. Child Abuse and Neglect, 29(12), 1359-1372.

Mandy, W., Chilvers, R., Chowdhury, U., Salter, G., Seigal, A., \& Skuse, D. (2012). Sex differences in autism spectrum disorder: evidence from a large sample of children and adolescents. Journal of Autism and Developmental Disorders, 42(7), 1304-1313. 
Mannion, A., Brahm, M., \& Leader, G. (2014). Comorbid psychopathology in autism spectrum disorder. Review Journal of Autism and Developmental Disorders, 1(2), 124-134.

Maras, K., Memon, A., Lambrechts, A. \& Bowler, D. (2013). Recall of a live and personally experienced eyewitness event by adults with autism spectrum disorder. Journal of Autism and Developmental Disorders. 43, (8), 1798 - 1810.

Mathersul, D., McDonald, S. \& Rushby, J. (2013). Understanding advanced theory of mind and empathy in high functioning adults with autism spectrum disorder. Journal of Clinical and Experimental Neuropsychology. 35, (6), $655-668$.

Matson, J. L., \& Williams, L. W. (2014). Depression and mood disorders among persons with autism spectrum disorders. Research in Developmental Disabilities, 35(9), 2003-2007.

Matson, J., Rieske, R. \& Williams, L. (2013). The relationship between autism spectrum disorders and attention deficit hyperactivity disorder: an overview. Research in Developmental Disabilities. 34, (9), 2475 - 2484.

Matson, J. \& Shoemaker, M. (2009). Intellectual disability and its relationship to autism spectrum disorders. Research in Developmental Disabilities. 30, (6), 1107 - 1114. 
Mazefsky, C., Folstein, S. \& Lainhart, J. (2008). Overrepresentation of mood and anxiety disorders in adults with autism and their first degree relatives: what does it mean? Autism Research. 1, (3), 193 - 197.

Mazefsky, C., Herrington, J., Siegel, M., Scarpa, A., Maddox, B., Scahill, L. \& White, S. (2013). The role of emotion regulation in autism spectrum disorder. Journal of the American Academy of Child and Adolescent Psychiatry. 52, (7), 679 - 688.

Melvin, C., Langdon, P. \& Murphy, G. (2017). Treatment effectiveness for offenders with autism spectrum conditions: a systematic review. Psychology, Crime \& Law. 23, 8, $748-$ 776.

Millon, T. (1998). Millon Clinical Multiaxial Inventory III). Pearson Assessments. Minneapolis: NCS Pearson, Inc.

Misra, P., Patel, M. \& Edwards, J. (2013). The need for specialist service for offenders with autistic spectrum disorder in high secure psychiatric care. European Psychiatry. 28, 1,

Moss, P., Howlin, P., Savage, S., Bolton, P., \& Rutter, M. (2015). Self and informant reports of mental health difficulties among adults with autism findings from a long-term follow-up study. Autism, 19(7), 832-841. 
Murphy, D., Bush, E. L., \& Puzzo, I. (2017). Incompatibilities and seclusions among individuals with an autism spectrum disorder detained in high secure psychiatric care. Journal of Intellectual Disabilities and Offending Behaviour. 8, 4, 188 - 200.

Murphy, D. \& Mullens, H. (2017). Examining the experiences and quality of life of patients with an autism spectrum disorder detained in high secure psychiatric care. Advances in Autism. 3(1), 3-14.

Murphy, D. \& McMorrow, K. (2015). View of autism spectrum conditions held by staff working in a high secure psychiatric hospital. Journal of Forensic Practice. 17 (3), 231 240.

Murphy, D. (2003). Admission details and cognitive profiles of male patients diagnosed with Asperger's syndrome detained in a special hospital: comparison with a schizophrenia and a personality disorder sample. The Journal of Forensic Psychiatry and Psychology. 14 (3), 506-524.

Murphy, D. (2006). Theory of mind in forensic patients with Asperger's syndrome, schizophrenia and a personality disorder. Cognitive Neuropsychiatry. 11(2), 99-111. 
Murphy, D. (2007) ${ }^{\mathrm{a}}$. Brief communication: Hare PCL-R profiles of male patients with Asperger's syndrome detained in high security psychiatric care. Journal of Forensic Psychiatry and Psychology. 18(1), 120-126.

Murphy, D. (2007) $)^{\mathrm{b}}$. Theory of mind and its relationship to clinical outcome, need and risk in mentally disordered offenders detained in high security psychiatric care. Criminal Behaviour and Mental Health.17, 300-311.

Murphy, D. (2010). Extreme violence in a young man with an autistic spectrum disorder: assessment and intervention within high security psychiatric care. Journal of Forensic Psychiatry and Psychology. 21 (3), 462-477.

Murphy, D. (2011). Establishing forensic psychiatric comparative data for the autistic spectrum quotient (AQ): examining its relationship with personality, neuropsychological functioning. Journal of Forensic Psychiatry and Psychology. 22 (4), 518-534.

Murphy, D. (2013). Risk assessment in Autism Spectrum Disorders. Journal of Learning Disabilities and Offending. 4 (1/1), 33-41.

Murphy, D. (2014). Self-reported anger among individuals with an autism spectrum disorder detained in high security psychiatric care. Journal of Forensic Psychiatry and Psychology. 25 (1), 100-112. 
Murphy, D. (2018). Interviewing individuals with an autism spectrum disorder in forensic settings. International Journal of Forensic Mental Health. https://doi.org/10.1080/149990 13.2018.1518939.

Murphy, G. H., Gardner, J., \& Freeman, M. J. (2017). Screening prisoners for intellectual disabilities in three English prisons. Journal of Applied Research in Intellectual Disabilities, 30(1), 198-204.

Murphy, G. H., Chiu, P., Triantafyllopoulou, P., Barnoux, M., Blake, E., Cooke, J., \& Beecham, J. K. (2017). Offenders with intellectual disabilities in prison: what happens when they leave? Journal of Intellectual Disability Research, 61(10), 957-968.

Myers, F. (2004). On the borderline? People with learning disabilities and or autistic spectrum disorders in secure, forensic and other specialist settings. Scottish Development Centre for Mental Health. Scottish Executive Social Research. The Stationary Office Bookshop. 71 Lothian Rd. Edinburgh. Scotland.

National Autistic Society. (2013). SPELL. Available at www.autism.org.uk/spell. 
NHS commissioning board, (2013). 2014/2015 NHS standard contract for high secure mental health services (adults). Particulars, schedule 2 - the services, A service specifications. NHS England.

Newman, S. \& Ghaziuddin, M. (2008). Violent crime in Asperger's syndrome: the role of psychiatric co-morbidity. Journal of Autism and Developmental Disorders. 38, 1848-1852.

Oliver, J., Huxley, P., Bridges, K. \& Mohammed, H. (1996). Quality of life and mental health services. London, Routledge.

Parsons, S. (2016). Authenticity in Virtual Reality for assessment and intervention in autism: A conceptual review. Educational Research Review, 19, 138-157.

Reinvall, O., Moisio, A. L., Lahti-Nuuttila, P., Voutilainen, A., Laasonen, M., \& Kujala, T. (2016). Psychiatric symptoms in children and adolescents with higher functioning autism spectrum disorders on the Development and Well-Being Assessment. Research in Autism Spectrum Disorders, 25, 47-57.

Radley, J., \& Shaherbano, Z. (2011). Asperger syndrome and arson: a case study. Advances in Mental Health and Intellectual Disabilities, 5(6), 32-36. 
Rivet, T. T., \& Matson, J. L. (2011). Review of gender differences in core symptomatology in autism spectrum disorders. Research in Autism Spectrum Disorders, 5(3), 957-976.

Robertson, C. E., \& McGillivray, J. A. (2015). Autism behind bars: a review of the research literature and discussion of key issues. The Journal of Forensic Psychiatry and Psychology, 26(6), 719-736.

Robinson, E. B., Lichtenstein, P., Anckarsäter, H., Happé, F., \& Ronald, A. (2013). Examining and interpreting the female protective effect against autistic behaviour. Proceedings of the National Academy of Sciences, 110(13), 5258-5262.

Rogers, J., Viding, E., Blair, J. \& Frith, U. (2006). Autism Spectrum Disorders and Psychopathy: shared cognitive underpinnings or double hit? Psychological Medicine. 36 (12), $1789-1798$

Rutter, M., LeCouteur, C. \& Lord, C. (2003). Autism Diagnostic Interview Revised. Pearson.

Schoenburg, P. \& David, A. (2014). Bio-feedback for psychiatric disorders: a systematic review. Applied Psychophysiology and Biofeedback. 39, 2, 109 - 135.

Sevlever, M., Roth, M. E., \& Gillis, J. M. (2013). Sexual abuse and offending in autism spectrum disorders. Sexuality and Disability, 31(2), 189-200. 
Scragg, P. \& Shah, A. (1994). Prevalence of Asperger's syndrome in a secure hospital.

British Journal of Psychiatry. 165, 679-682.

Shively, R. (2014). Treating offenders with mental retardation and developmental disabilities. Corrections Today. 66, $84-87$.

Søndenaa, E., Helverschou, S. B., Steindal, K., Rasmussen, K., Nilson, B., \& Nøttestad, J. A. (2014). Violence and sexual offending behaviour in people with autism spectrum disorder who have undergone a psychiatric forensic examination. Psychological Reports, 115(1), 3243.

Spain, D., O’Neil, L., Harwood, L. \& Chaplin, E. (2016). Psychological interventions for adults with ASD: clinical approaches. Advances in Autism. 2, 1, 24 -30.

Speilberger, C. (1999). Manual for the State Trait Anger Expression Inventory - 2. Odessa, FL. Psychological Assessment Resources.

Taylor, M. J., Charman, T., \& Ronald, A. (2015). Where are the strongest associations between autistic traits and traits of ADHD? Evidence from a community-based twin study. European Child and Adolescent Psychiatry, 24(9), 1129-1138. 
Taylor, J. L., \& Gotham, K. O. (2016). Cumulative life events, traumatic experiences, and psychiatric symptomatology in transition-aged youth with autism spectrum disorder. Journal of Neurodevelopmental Disorders, 8(1), 28.

Think Autism: fulfilling and rewarding lives. The strategy for adults with autism in England: an update. (2014). Available

Assets.publishing.service.gov.uk/government/uploads/system/uploads/attachment_data/file/2 99866/Autism_Strategy.pdf.

Transforming Care. Model Service Specifications Supporting Implementation of the Service Model. A resource for commissioners to develop service specifications to support implementation of the national service model for people with a learning disability and or autism who display behaviour that challenges, including those with a mental health condition. (2017). HNS England. www.england.hns.uk / wp-content/uploads/2017/model-service-spec2017.

van Wijngaarden-Cremers, P. J., van Eeten, E., Groen, W. B., van Deurzen, P. A., Oosterling, I. J., \& van der Gaag, R. J. (2014). Gender and age differences in the core triad of impairments in autism spectrum disorders: A systematic review and meta-analysis. Journal of Autism and Developmental Disorders, 44(3), 627-635. 
Veselinova, C. (2014). Introductory awareness of autistic spectrum conditions. Nursing and Residential Care, 16(1), 40-44.

Wachtel, L. \& Shorter, E. (2013). Autism plus psychosis: A 'one-two punch' risk for tragic violence? Medical Hypotheses. 81, (3), $404-409$.

Werling, D. M., \& Geschwind, D. H. (2013). Sex differences in autism spectrum disorders. Current Opinion in Neurology, 26(2), 146.

Wing, L. (1980). The MRC Handicaps, Behaviour \& Skills (HBS) schedule. Acta Psychiatrica Scandinavica. 62, $241-248$.

Wing, L. (1981). Asperger's syndrome: a clinical account. Psychological Medicine. 11, 115 13.

Wing, L. (1997). Asperger's syndrome: management requires diagnosis. Journal of Forensic Psychiatry. 2, 8, 253-257.

World Health Organisation (2018). International Classification of Mental Disorders $11^{\text {th }}$ edition. Geneva.

Worthington, R. (2016). What are the key skills that staff require to support adults on the autism spectrum effectively? British Psychological Society. Division of Forensic Psychology. Forensic Update. A Compendium of the main articles in issues 121, $122 \& 123.61 \& 69$. 
Zwaigenbaum, L., Bryson, S. E., Szatmari, P., Brian, J., Smith, I. M., Roberts, W., et al. (2012). Sex differences in children with autism spectrum disorder identified within a highrisk infant cohort. Journal of Autism and Developmental Disorders, 42(12), 2585-2596. 